\title{
Prediction of Adverse Pregnancy Outcome Related to Placental Dysfunction Using the sFlt-1/PIGF Ratio: A Narrative Review
}

\section{Vorhersage eines ungünstigen Schwangerschaftsoutcomes bei plazentarer Dysfunktion anhand des sFlt-1/PIGF-Quotienten: Eine narrative Übersichtsarbeit}

\section{(두)(1) (오 $\ominus$}

\author{
Authors \\ Oliver Graupner ${ }^{1,2}$, Christian Enzensberger ${ }^{1}$ \\ Affiliations \\ 1 Department of Obstetrics and Gynecology, University \\ Hospital Aachen, RWTH University, Aachen, Germany \\ 2 Department of Obstetrics and Gynecology, University \\ Hospital rechts der Isar, Technical University, Munich, \\ Germany
}

\section{Key words}

(anti-)angiogenic factors, placental growth factor, soluble fms-like tyrosine kinase 1 , preeclampsia, fetal growth restriction, adverse perinatal outcome

\section{Schlüsselwörter}

(anti-)angiogene Faktoren, plazentarer Wachstumsfaktor, lösliche Fms-ähnliche Tyrosinkinase 1, Präeklampsie, fetale Wachstumsrestriktion, ungünstiges perinatales Outcome
received
5. 12.2020
accepted after revision
27.2. 2021

Bibliography

Geburtsh Frauenheilk 2021; 81: 948-954

DOI 10.1055/a-1403-2576

ISSN 0016-5751

(C) 2021. The Author(s).

This is an open access article published by Thieme under the terms of the Creative Commons Attribution-NonDerivative-NonCommercial-License, permitting copying and reproduction so long as the original work is given appropriate credit. Contents may not be used for commercial purposes, or adapted, remixed, transformed or built upon. (https://creativecommons.org/licenses/by-nc-nd/4.0/)

Georg Thieme Verlag KG, Rüdigerstraße 14,

70469 Stuttgart, Germany

Correspondence

PD Dr. Oliver Graupner

Department of Obstetrics and Gynecology,

University Hospital Aachen, RWTH University

Pauwelsstraße 30, 52074 Aachen, Germany

ograupner@ukaachen.de

\begin{abstract}
The sFlt-1 (soluble fms-like tyrosine kinase-1)/PIGF (placental growth factor) ratio is a helpful tool for the prediction and diagnosis of preeclampsia (PE). Current data even show that the ratio has the potential to predict adverse pregnancy outcomes (APO) caused by placental pathologies. The aim of this article is to give a brief overview of recent findings on APO predictions based on the sFlt-1/PIGF ratio. The focus is on obstetric pathologies related to placental dysfunction (PD) such as PE and/or fetal growth restriction (FGR). New uses of the sFlt-1/PIGF ratio as a predictor of APO demonstrate its potential with regard to planning hospitalization and corticosteroid administration and the optimal timing of delivery. However, prospective interventional studies are warranted to define the exact role of the sFlt-1/PIGF ratio as a predictor of adverse pregnancy outcomes caused by placental pathologies.
\end{abstract}

\section{ZUSAMMENFASSUNG}

Der sFlt-1-(lösliche Fms-ähnliche Tyrosinkinase-1)/PIGF-(plazentarer Wachstumsfaktor-)Quotient ist ein nützliches Werkzeug für die Prognose und Diagnose einer Präeklampsie (PE). Aktuelle Daten zeigen sogar, dass der Quotient das Potenzial hat, durch plazentare Pathologien hervorgerufene ungünstige perinatale Outcomes (APO) vorherzusagen. Dieser Artikel gibt einen kurzen Überblick über die neuesten Erkenntnisse zu APO-Vorhersagen, die auf dem Einsatz des sFlt-1/PIGF-Quotienten basieren. Im Mittelpunkt stehen geburtshifliche Pathologien, die durch eine plazentare Dysfunktion (PD) wie PE und/oder fetale Wachstumsrestriktion (FGR) hervorgerufen werden. Neue Einsatzfelder für den sFlt-1/PIGF-Quotienten als Prädiktor von APO zeigen sein Potenzial bei der Planung einer Einweisung ins Krankenhaus bzw. der Verabreichung von Kortikosteroiden sowie für die optimale Terminierung einer Entbindung. Prospektive interventionelle Studien sind notwendig, um die präzise Rolle des sFlt-1/PIGF-Quotienten als Prädiktor von ungünstigen Schwangerschaftsergebnissen, die durch plazentare Pathologien hervorgerufen werden, zu ermitteln. 


\section{Introduction}

Obtained from maternal serum, pro- (PIGF: placental growth factor) and anti- (sFlt-1: soluble fms-like tyrosine kinase 1) angiogenic factors and their ratio (sFlt-1/PIGF) have become an integral part of the prediction and diagnosis of preeclampsia (PE) in the last decade. However, there is increasing evidence that the sFlt$1 /$ PIGF ratio could play a role not only in the diagnosis of $P E$ but also in the prediction of adverse pregnancy outcomes (APO) and thus provide important information for the optimal timing of delivery. The ratio could help with decision-making when inpatient monitoring and fetal lung maturation are being considered. Strongly elevated sFlt-1/PIGF ratios in early and late-onset PE have been shown to be correlated with the necessity of delivering the fetus within 48 hours and the need for immediate and careful clinical monitoring [1-5]. Recent data on the use of the sFlt-1/PIGF ratio for APO prediction (including serious maternal and neonatal morbidity and fetal/neonatal mortality) in placental disease and unselected pregnancies remains controversial. Some authors found that it had a predictive value [6-10], others reported that the sFlt-1/PIGF ratio only had a low to moderate use for the prediction of APO [11-14]. In general, a high sFlt-1/PIGF ratio is related to placental dysfunction (PD), which may be an indication of PE but also of fetal growth restriction (FGR) [15-17]. Combined with ultrasound (fetal biometry, fetomaternal Doppler), the sFlt1/PIGF ratio appears to be useful as a supplementary criterion not only for the detection of FGR [18] but also for the prediction of the time-to-delivery interval and associated APO in isolated FGR cases $[19,20]$.

The aim of this narrative review is to give a brief overview of recent findings on the use of the sFlt-1/PIGF ratio for the prediction of APO in placental pathologies such as PE and FGR. The focus is particularly on studies which attempted to correlate the sFlt-1/ PIGF ratio of PE/FGR cases with the short-term perinatal outcome (fetomaternal morbidity and mortality). Studies on the screening of high and low-risk groups during pregnancy to predict early or late-onset PE/FGR will not be discussed in this review. However, the advances in PE/FGR prediction models in the first and second trimester are immanent [21-23] and efforts to extract the best prediction models from large datasets are ongoing [24]. It should be mentioned that this review is not a systematic analysis of the existing literature but a selective presentation of articles related to this topic the authors considered interesting.

\section{Review}

\section{Preeclampsia: A new definition reflecting its syndromic character}

Up until 2013, PE was considered to be the result of a combination of hypertension and proteinuria after the 20th week of pregnancy. However, in 2013, the ACOG's hypertension task force changed the definition of PE to include the presence of pathological features with or without proteinuria, such as thrombocytopenia, poor liver function, new-onset renal insufficiency, pulmonary edema, or new-onset cerebral or visual disturbances [25]. The definition did not include a combination of hypertension and the sFlt-1/
PIGF ratio based on gestational age-specific cutoff values, as recommended in the consensus statement [5]: <38 exclusion of PE (gestational age independent) for at least one week; $>85$ (angiogenic) diagnosis of early-onset PE $<34$ weeks; $>110$ (angiogenic) diagnosis of late-onset $P E \geq 34$ weeks. Assuming that the placenta plays a decisive role in the pathogenesis of $\mathrm{PE}$ and based on the fact that an elevated sFlt-1/PIGF ratio is an indication of PD, a combination of hypertension and an increase in the sFlt-1/PIGF ratio above the cutoff values was considered to be another definition of PE and was included in the German, Austrian and Swiss guidelines [26]. This underlines the understanding of the PE as an "angiogenic-placental syndrome", which according to some authors better reflects the pathophysiology of different clinical manifestations as a result of a placenta-generated anti-angiogenic state [27]. Lai et al. recently investigated the ability of the definitions of PE at term ( $\geq 37$ weeks) proposed by the ACOG and the International Society for the Study of Hypertension in Pregnancy (ISSHP) [28] to identify APO. Their data on 15248 singleton pregnancies revealed that the ability to identify women with $P E$ varied according to the definition and suggested that, compared with the traditional (ACOG) definition, a broad definition (ISSHP) of PE which included maternofetal factors plus an angiogenic imbalance (defined as PIGF < 5th percentile or a sFlt-1/PIGF ratio $>95$ th percentile) best identified women and neonates at risk of adverse outcomes [29].

\section{Preeclampsia: sFlt-1/PIGF ratio-related APO, time- to-delivery interval and clinical decision-making}

Recent studies reported an association between APO, a significantly reduced time-to-delivery interval and an increased sFlt-1/ PIGF ratio in cases with PE $[6,11]$. With regard to PD, the most common APO in PE is iatrogenic preterm delivery [27]. It should be mentioned that, so far, there is no general standard for the definition and reporting of PE-related APO. On the contrary, the reporting of maternal and neonatal outcomes varies greatly [30]. To overcome this problem and standardize the reporting of PE-related outcomes, Duffy et al. recently published an international Delphi consensus on a core outcome set for PE which should be used in future studies [31].

Below, the results of previously published studies investigating different scenarios and cutoff values for the sFlt-1/PIGF ratio in suspected or confirmed cases of PD are described. Cases with suspected or confirmed PE who had an intermediate sFlt-1/PIGF ratio (> 38 and $\leq 85$ at $<34$ weeks or $>38$ and $\leq 110 \geq 34$ weeks) were found to be at risk of a shorter time-to-delivery interval and at higher risk of preterm delivery (<37 weeks) [8,24]. Hoffman et al. investigated 83 patients with an intermediate sFlt-1/PIGF ratio. PE developed in $31.3 \%$ of cases, although in the majority of cases (65.4\%) PE was mild or moderate. APO occurred in $36.1 \%$ of cases and severe PE in $10.8 \% .92 \%$ of patients, tested at $<34+0$ weeks, delivered prematurely. The overall preterm birth rate was $27.7 \%$. However, the authors did not use 38 but 33 as the PE exclusion cutoff value for sFlt-1/PIGF [8]. These results are in line with those reported by Bednarek-Jędrzejek et al. In their study, they divided 927 pregnant patients between 18 and 41 weeks of gestation with any form of PD (PE/HELLP syndrome/gestational hypertension, FGR, placental abruption) into three subgroups according 
to their sFlt-1/PIGF ratios ( $<38,38-85$ and $>85$ ) and looked at differences in the occurrence of APO and the time-to-delivery interval. A comparison of the sFlt-1/PIGF $<38$ group $(n=525)$ with the 38-85 group ( $n=177$ ) showed a significantly shorter time-to-delivery interval (16 vs. 3 days) and a lower gestational age at delivery in the intermediate group (38 vs. 37 weeks). Biochemical factors associated with HELLP syndrome were significantly more often abnormal, and systolic as well as diastolic blood pressure was significantly higher in the intermediate group. There were no significant differences between both groups with regard to APO, including lower neonatal birth weight and umbilical cord blood $\mathrm{pH}$. However, the authors did not differentiate between the sFlt$1 /$ PIGF cutoff value for angiogenic early (> 85 at $<34$ weeks) and late ( $>110$ at $\geq 34$ weeks) onset $\mathrm{PE}$, and the study population was very heterogeneous, with varying degrees of PD severity [9].

A further simplification of risk stratification in cases with suspected $\mathrm{PE}$ based on sFlt-1/PIGF cutoff values recently showed that patients with a ratio of $>38$ were at greater risk of imminent delivery compared to patients with a ratio $\leq 38$ [32]. This clearly shows the importance of careful clinical follow-up and retesting (carried out one or two weeks after the initial test) of patients with an intermediate sFlt-1/PIGF ratio, irrespective of their current clinical symptoms [5]. In the case of suspected late-onset PE an intermediate sFlt-1/PIGF ratio may be interpreted as a sign of impending PD, which should give reason to think about an induction of labour, especially if there are further signs of PD (e.g., feto-maternal Doppler abnormalities).

In cases with suspected or confirmed PE and a sFlt-1/PIGF ratio defined as angiogenic early-onset PE (ratio > 85 at $<34$ weeks), delivery occurred within 2 weeks in $86.0 \%$, compared with $15.8 \%$ of patients who had values of < 85 [1]. In their "real world study", the Verlohren group recently investigated the clinical use of the sFlt-1/PIGF ratio alone or in combination with other clinical tests to predict APO in patients with signs and symptoms of PE. They evaluated the sFlt-1/PIGF cutoff values of 38 and 85 and their integration into a multimarker model in 1117 subjects. Patients with an APO had a median sFlt-1/PIGF ratio of 177 compared with patients without APO who had a median value of 14 . Using the sFlt-1/PIGF cutoff values, risk was stratified into high ( $>85)$, intermediate (38-85), and low (<38). High and intermediate risk patients had a significantly shorter time to delivery compared to low-risk patients (4 vs. 8 vs. 29 days). When all available clinical information was integrated into a multimarker model, the area under the curve amounted to $88.7 \%$. In contrast, the sFlt-1/PIGF ratio alone was inferior to the full model, with an area under the curve of $85.7 \%$ [33]. This is in line with the findings of Perry et al., who reported on the additive value of the sFlt-1/PIGF ratio in a multimarker model (which included both maternal risk factors and the sFlt-1/PIGF ratio) to predict the need for delivery within 1 week or 2 weeks from assessment. However, their results showed that a continuous scale approach using angiogenic markers appeared to be superior to a cutoff-based approach [34].

The evaluation of APO risk in cases with very high sFlt-1/PIGF values (> 655 at $<34$ weeks; > 201 at $\geq 34$ weeks) is currently of great interest. Older data has indicated that short-term complications and the need to deliver are highly probable when the sFlt-1/ PIGF value is very high, with only $30 \%$ of patients still pregnant after 2 days [2]. Recent data, however, suggest that a sFlt-1/PIGF ratio of more than 655 is not predictive of APO in early-onset PE and that an extremely high sFlt-1/PIGF ratio > 1000 might be more useful for APO prediction. Stolz et al. retrospectively analyzed data from singleton pregnancies who presented with clinically manifest PE and had an immediate sFlt-/PIGF assessment. Cases with a sFlt-1/PIGF ratio of $\geq 655(n=30)$ were matched $1: 1$ for gestational age to controls with a ratio of $<655(n=30)$. A sFlt$1 / \mathrm{PIGF}$ ratio $\geq 655$ was not predictive of APO including 5-min Apgar score, arterial cord $\mathrm{pH}$, perinatal mortality and FGR. However, there was a significant association between a sFlt-1/PIGF ratio $\geq 655$ and fetal distress (40\% in cases vs. $3.3 \%$ in controls) and neonatal sepsis ( $23.3 \%$ vs. $0 \%$ ). A diagnosis of FGR as well as respiratory distress was more common in cases with sFlt-1/PIGF ratios $\geq 1000$ [11]. However, the authors did not investigate substantial maternal adverse outcomes underlying sFlt-1/PIGF ratios $>655$.

In contrast, Villalain et al. demonstrated that a sFlt-1/PIGF ratio of $>655$ was almost invariably associated with PD in the form of PE or progressive FGR [6]. In their multicenter retrospective cohort study, they analyzed 237 singleton pregnancies between $20+0$ and $37+0$ weeks of gestation included at the time of first identifying a sFlt-1/PIGF ratio $>655$. Reasons to carry out a sFlt-1/PIGF ratio assessment were

1. clinical suspicion of PD, including the presence of signs and symptoms suggestive of $\mathrm{PE}$, abnormal uterine artery Doppler at $24+0$ to $28+6$ weeks, and early-onset FGR (diagnosed at $<32+0$ weeks), and

2. serial follow-up in cases diagnosed with PE or FGR.

The risk of serious maternal morbidity was high at any gestational age (>30\%), as was the risk of severe perinatal morbidity and mortality before 29 to 30 weeks (> 50\%). If a value > 655 was detected before 24 weeks, perinatal mortality and severe perinatal morbidity was as high as $62 \%$ and $90 \%$, respectively. Conversely, perinatal outcomes improved significantly when an sFlt-1/PIGF ratio $>655$ was detected from 29 weeks, with much lower rates of perinatal mortality or severe morbidity. Interestingly, these outcomes did not differ significantly between cases with and without PE at the time of the first sFlt-1/PIGF of $>655$. This reinforces the assumption that a strict distinction between early PE and FGR with regard to APO may be outdated and that instead both entities should be interpreted as different expressions of severe PD [6]. Furthermore, in contrast to older studies, $60.5 \%$ of patients with a ratio $>655$ remained pregnant after 48 hours [6]. However, when the ratio is > 655 (regardless of whether it is isolated early-onset PE and/or FGR), these patients should immediately be referred to a perinatal center for close monitoring of the mother and fetus. Because on the much shorter time-to-delivery interval due to the high risk of imminent severe APO, the administration of corticosteroids for fetal lung maturation should be strongly considered. An overview of recent studies on greatly elevated sFlt-1/PIGF ratios (> 655) in cases with suspected PD is given in > Table 1.

Little is known about APO prediction for late-onset PE ( $\geq 34$ weeks) cases with a sFlt-1/PIGF ratio $>201$. A recent analysis of eight patients with angiogenic late-onset PE and a sFlt-1/PIGF ratio $>201$ revealed a higher likelihood of NICU admission, late 
- Table 1 Overview of recent studies on greatly elevated sFlt-1/PIGF ratios in cases with suspected placental dysfunction (preeclampsia and/or fetal growth restriction). Clinical setting of sFlt-1/PIGF determination, published data on adverse perinatal outcome (APO), and time-to-delivery interval as well as possible conclusions are shown.

\begin{tabular}{|c|c|c|c|}
\hline $\begin{array}{l}\text { Greatly elevated } \\
\text { sFlt-1/PIGF in sus- } \\
\text { pected cases of PD } \\
\text { (PE and/or FGR) }\end{array}$ & Clinical setting & $\begin{array}{l}\text { Published data on APO and } \\
\text { time to delivery }\end{array}$ & Conclusion \\
\hline \multirow[t]{3}{*}{$\geq 655$ at $<34$ weeks } & $\begin{array}{l}\text { - Retrospective cohort study } \\
\text { - Total number of patients: } \mathrm{n}=237 \\
\text { - with PE: } \mathrm{n}=185 \\
\text { ( } 77.3 \% \text { with FGR) } \\
\text { - without PE: } \mathrm{n}=52 \\
\quad(82.7 \% \text { with FGR) } \\
\text { - Included at the time of first } \\
\text { identification of a } \\
\text { sFlt- } 1 / \text { PIGF ratio }>655\end{array}$ & $\begin{array}{l}\text { Villalaín et al. [6]: } \\
\text { - Median time to delivery: } 4 \text { days (PE) } \\
\text { and } 7 \text { days (without PE) } \\
\text { - Perinatal mortality: } 62.1 \% \text { before } \\
24 \text { weeks } \\
\text { - Severe neonatal morbidity (> } 50 \% \text { ) before } \\
29 \text { weeks but did not occur after } 34 \text { weeks } \\
\text { - Maternal severe morbidity > } 30 \% \text { at any } \\
\text { GA }\end{array}$ & $\begin{array}{l}\text { - Both mother and fetus should } \\
\text { be closely monitored } \\
\text { - Consider fetal lung maturation } \\
\text { and maternal hospitalization }\end{array}$ \\
\hline & $\begin{array}{l}\text { - Retrospective cohort study } \\
\text { - Cases with sFlt- } 1 / \text { PIGF ratio } \geq 655 \\
(n=30) \text { were matched } 1: 1 \text { for } \\
\text { gestational age to controls with } \\
\text { a ratio }<655(n=30)\end{array}$ & $\begin{array}{l}\text { Stolz et al. [11]: } \\
\text { - No predictive value for APO including } \\
\text { 5-min Apgar, arterial cord pH, perinatal } \\
\text { mortality and FGR } \\
\text { - Significant association with fetal distress } \\
\text { ( } 40 \% \text { in cases vs. } 3.3 \% \text { in controls) and } \\
\text { neonatal sepsis ( } 23.3 \% \text { vs. } 0 \%) \\
\text { - FGR diagnosis and respiratory distress } \\
\text { more common in cases with a ratio } \geq 1000\end{array}$ & $\begin{array}{l}\text { - An extremely high sFlt-1/PIGF ra- } \\
\text { tio > } 1000 \text { might be more useful } \\
\text { for APO prediction }\end{array}$ \\
\hline & $\begin{array}{l}\text { - Retrospective cohort study } \\
\text { - Cases }(n=76) \text { with early-onset PE } \\
\text { (sFlt-1/PIGF ratio > 655) and } \\
\text { expectant management }\end{array}$ & $\begin{array}{l}\text { Simón et al. [12]: } \\
\text { - Mean time to delivery for cases with a ratio } \\
>655 \text { vs. } \leq 655: 4.4 \text { vs. } 12.1 \text { days } \\
\text { - } \text { Relative risk of delivery within } 48 \mathrm{~h} \text { for } \\
\text { a sFlt-1/PIGF ratio > } 655 \text { was } 5.3\end{array}$ & $\begin{array}{l}\text { - A sFlt-1/PIGF ratio > } 655 \text { at diag- } \\
\text { nosis was associated with a } 5 \text {-fold } \\
\text { higher risk of delivery within } \\
\leq 48 \mathrm{~h} \\
\text { - Poor predictive performance for } \\
\text { adverse maternal or perinatal } \\
\text { outcome }\end{array}$ \\
\hline
\end{tabular}

PD: placental dysfunction, PE: preeclampsia, FGR: fetal growth restriction, GA: gestational age

preterm birth, lower gestational age at delivery and lower birth weight compared to cases with sFlt-1/PIGF values $\leq 201(n=59)$. Confirming the results from Verlohren et al. [2], 66.7\% of patients with a sFlt-1/PIGF ratio $>201$ delivered within the first $48 \mathrm{~h}$. After 7 days, no patient with a sFlt-1/PIGF ratio $>201$ was still pregnant [13]. The data on the optimal time of delivery (before $37+0$ weeks of gestation or from $37+0$ weeks of gestation) to achieve the best neonatal and maternal outcome in cases with late-onset $P E$ is currently still not clear $[35,36]$. Women with a ratio $>201$ may be a particularly interesting subgroup when considering changes in clinical decision-making, not only in terms of clinical monitoring but also with regard to the question of inducing labor before 37 weeks. The possibility of inducing labor before $37+0$ weeks of gestation should be discussed with patients who have confirmed (even if only mild) late-onset PE and a ratio > 201 .

\section{Fetal growth restriction: New definition reflecting the main clinical characteristics of early and late FGR}

Previously, the definitions of early and late-onset FGR varied. This makes the Delphi consensus on the criteria for a diagnosis of FGR particularly important, as it has established a uniform definition for early (<32 weeks) and late-onset ( $\geq 32$ weeks) FGR [37]. The new definition has also found its way into international guidelines [38]. Early-onset FGR is defined as

1. abdominal circumference (AC)/estimated fetal weight (EFW) $<3 r$ centile, or

2. umbilical artery (UA) with absent end-diastolic flow (AEDF), or

3. $A C / E F W<10$ th centile combined with mean uterine artery pulsatility index (mUtA-PI) $>95$ th centile, and/or

UA-PI > 95th centile.

Late-onset FGR is defined as AC/EFW < 3rd centile, or at least two out of three of the following:

1. AC/EFW $<10$ th centile,

2. AC/EFW crossing centiles $>2$ quartiles on growth centiles

3. cerebroplacental ratio $(C P R)<5$ th centile or UA-PI $>95$ th centile

The characteristics of the two FGR entities are reflected in these definitions, including the severity of PD and co-incidence of PE. 
- Table 2 Overview of recent studies on the determination of sFIt-1/PIGF in isolated early (<32 weeks) and late-onset ( $\geq 32$ weeks) small-for-gestational-age and fetal growth restriction. Clinical setting at the time of sFlt-1/PIGF determination, published data on adverse perinatal outcomes (APO), and time-to-delivery intervals as well as possible conclusions are shown.

\begin{tabular}{|c|c|c|c|}
\hline $\begin{array}{l}\text { sFIt-1/PIGF } \\
\text { in SGA/FGR }\end{array}$ & Clinical setting & $\begin{array}{l}\text { Published data on APO and } \\
\text { time-to-delivery interval }\end{array}$ & Conclusion \\
\hline \multirow{4}{*}{$\begin{array}{l}\text { Early-onset } \\
\text { at }<32 \text { weeks }\end{array}$} & \multirow{3}{*}{$\begin{array}{l}\text { - EFW }<3 \text { rd centile or EFW }<10 \text { th centile } \\
\text { combined with } \\
\text { - UA PI }>95 \text { th centile or } \\
\text { - MCA PI }<5 \text { th centile or } \\
\text { - CPR }<5 \text { th centile } \\
\text { - antegrade flow in UA Doppler } \\
\text { assessment } \\
\text { - } \text { sFlt-1/PIGF }<85(n=30) \text { or } \geq 85 \\
(n=90)\end{array}$} & Quezada et al. [19]: & \\
\hline & & $\begin{array}{l}\text { sFlt- } 1 / \text { PIGF }<85 \\
\text { - Need to deliver within } 1 \text { week: } 0 \% \\
\text { - Interval to delivery prolonged for } \\
\geq 4 \text { weeks in }>70 \% \\
\text { - Significantly fewer APO (28.6\%) }\end{array}$ & $\begin{array}{l}\text { - No need for hospitalization and lung } \\
\text { maturation } \\
\text { - Careful outpatient monitoring } \\
\text { - Reassuring status when FGR diagnosis } \\
\text { is made near viability }\end{array}$ \\
\hline & & $\begin{array}{l}\text { sFlt-1/PIGF } \geq 85 \\
\text { - } \text { Need to deliver within } 1 \text { week: } 36 \% \\
\text { - Interval to delivery prolonged for } \\
\geq 4 \text { weeks in }<20 \% \\
\text { - Significantly more APO ( } 53.7 \%)\end{array}$ & $\begin{array}{l}\text { - Consider hospitalization and fetal lung } \\
\text { maturation }\end{array}$ \\
\hline & $\begin{array}{l}\text { - EFW }<10 \text { th centile: prediction models } \\
\text { (fetomaternal Doppler/medical history } \\
\pm \text { sFIt- } 1 / \text { PIGF) to assess individual risk } \\
\text { for APO and the need for elective } \\
\text { delivery at }<30,<34 \text { or }<37 \text { weeks }\end{array}$ & $\begin{array}{l}\text { Mendoza et al. [20]: } \\
\text { - No significant differences between the } \\
\text { model with sFlt-1/PIGF and sFlt-1/PIGF } \\
\text { alone } \\
\text { - Model without sFlt-1/PIGF: poorer } \\
\text { overall performance compared with } \\
\text { the multivariable model with sFlt-1/ } \\
\text { PIGF to predict delivery at < } 30 \text { weeks, } \\
\text { at<37 weeks and APO }\end{array}$ & $\begin{array}{l}\text { - Complementary use of sFlt-1/PIGF ra- } \\
\text { tio leads to better prenatal counseling } \\
\text { of parents from the time of diagnosis of } \\
\text { SGA/FGR } \\
\text { - Since Doppler changes usually occur } \\
\text { sequentially during follow-up it is not } \\
\text { possible to determine the risk of APO } \\
\text { after the initial assessment }\end{array}$ \\
\hline $\begin{array}{l}\text { Late-onset } \\
\text { at } \geq 32 \text { weeks }\end{array}$ & $\begin{array}{l}\text { - EFW < 10th centile: association be- } \\
\text { tween fetomaternal Doppler indices } \\
\text { (mUtA-PI, CPR) and sFlt-1/PIGF with } \\
\text { APO }\end{array}$ & $\begin{array}{l}\text { Lobmaier et al. [44]: } \\
\text { - The combination of Doppler indices } \\
\text { and angiogenic factors did not signifi- } \\
\text { cantly improve the prediction of APO }\end{array}$ & $\begin{array}{l}\text { (Anti-)angiogenic factors have a pre- } \\
\text { dictive value that is similar to that of } \\
\text { fetomaternal Doppler for the identifi- } \\
\text { cation of APO }\end{array}$ \\
\hline
\end{tabular}

EFW: estimated fetal weight, UA: umbilical artery, mUtA-PI: mean uterine artery pulsatility index, MCA: middle cerebral artery, CPR: cerebroplacental ratio, $\mathrm{Pl}$ : pulsatility index

\section{Fetal growth restriction: sFlt-1/PIGF ratio-related APO, time-to-delivery interval and clinical decision-making}

The main clinical challenge in early FGR is its obstetric management, while for late FGR it is detection, as UA Doppler findings are generally normal [37-39]. To date, predicting APO in FGR focused mainly on fetoplacental Doppler and computerized CTG (c-CTG)-derived short-term variation (STV) findings and their deterioration [37-40]. The sFlt-1/PIGF ratio could be used to complement ultrasound examinations. Given that a cascade of Doppler parameter deterioration usually occurs during follow-up of FGR [41], it is not possible to determine the risk of APO after the initial Doppler examination. Repeated and frequent Doppler examinations are necessary to assess the risk of intrauterine mortality and short- and long-term childhood morbidity [20]. Data from the TRUFFLE trial have clearly shown that the most effective obstetric management of early-onset FGR consists of a combination of fetal monitoring based on ductus venosus Doppler and c-CTGbased STV $[40,42]$. However, recent data also show that the sFlt$1 /$ PIGF ratio has the potential to act as a supplementary criterion in clinical decision-making. In cases with early FGR, fetoplacental Doppler findings can make it difficult to come to a clear decision in favor of hospitalization and lung maturation. Antegrade end-diastolic UA flow with a PI > 95th centile or signs of cerebral redis- tribution (middle cerebral artery PI or CPR $<5$ th centile) can be a critical Doppler finding. Quezada et al. recently demonstrated that there was a good correlation between the sFlt-1/PIGF ratio (using the same cutoff of $>85$ as for angiogenic early-onset PE) at the time of FGR diagnosis with antegrade umbilical artery flow and the need to deliver. In their prospective observational study of 120 cases, a sFlt-1/PIGF ratio $<85$ at the time of diagnosis of earlyonset FGR with antegrade UA flow identified a group of pregnancies for whom the need to deliver within 1 week was $0 \%$ and the interval to delivery was expected to be prolonged for $\geq 4$ weeks in $>70 \%$ cases. The authors concluded that determination of the sFlt-1/PIGF ratio in early-onset FGR with antegrade umbilical artery flow might be helpful in planning maternal and fetal monitoring, corticosteroid administration and patient allocation [19]. Similarly, a small study evaluated the predictive value of the sFlt$1 /$ PIGF ratio to identify fetuses with a higher risk of APO in a cohort of 34 women with FGR diagnosed at $<34$ weeks. The authors reported that a sFlt-1/PIGF ratio $\geq 86.2$ resulted in maximum detection of pregnancies at risk of APO [43].

Generally, Doppler abnormalities in early FGR can predict the occurrence of short-term complications. However, normal fetal Doppler values at the time of diagnosis do not exclude their occurrence in the long term. With this in mind, Mendoza et al. devel- 
oped predictive models which included the sFlt-1/PIGF ratio, EFW, fetomaternal Doppler and maternal risk factors for PD to assess the individual risk for APO and preterm delivery in early-onset small-for-gestational-age (SGA: EFW < 10th centile, $\mathrm{n}=29$ ) and FGR $(n=124)$ pregnancies. When the areas under the curve were compared between models, no statistically significant differences were observed between the model with the sFlt-1/PIGF ratio and the model using the sFlt-1/PIGF ratio alone. However, the model without the sFlt-1/PIGF ratio had a poorer overall performance compared with the multivariable model with the sFlt-1/PIGF ratio in terms of its ability to predict delivery at $<30$ weeks, delivery at $<37$ weeks and APO [20]. This shows that complementary use of the ratio may possibly improve the counseling offered to parents with a SGA/FGR fetus.

Similar to late-onset PE, the data for late FGR and the prognostic value of the sFlt-1/PIGF ratio with regard to APO is also limited. Lobmaier et al. compared the value of Doppler monitoring with sFlt-1, PIGF and the sFlt-1/PIGF ratio at the time of diagnosis of late-onset SGA for the prediction of APO. They found that (anti-) angiogenic factors have a predictive value that is similar to that of Doppler indices for the identification of APO associated with lateonset FGR [44]. An overview of recent studies on the determination of the sFlt-1/PIGF ratio in isolated early ( $<32$ weeks) and lateonset ( $\geq 32$ weeks) small-for-gestational-age and fetal growth restriction is shown in $>$ Table 2.

Recent data from the TRUFFLE group showed that signs of cerebral blood flow redistribution are associated with APO in lateonset SGA fetuses [45]. However, the question of whether changes in the middle cerebral artery $\mathrm{PI}$ and/or umbilicocerebral ratio reflecting cerebrovascular redistribution are signs of the severity of the PD or even independent predictors of short- and long-term sequalae of affected fetuses will remain unanswered until the results of the TRUFFLE 2 trial come out. In view of the promising results of a sFlt-1/PIGF-mediated outcome prediction in early-onset FGR, this appears to be an ideal opportunity for future studies to also include (anti-)angiogenic markers when considering what constitutes optimal obstetric management.

\section{Conclusion}

This review examined the sFlt-1/PIGF-ratio as a predictor of APO in cases with placental disease. New uses of the sFlt-1/PIGF ratio as a predictor of APO show its potential when it comes to planning hospitalization, lung maturation, and particularly the optimal timing of delivery. In the opinion of some authors, the sFlt-1/PIGF ratio could be the perfect tool which could serve as an objective surrogate for the degree of PD [19]. The impact of the ratio on clinical decision-making in routine clinical practice is growing $[46,47]$. However, the trend in PE/FGR research is moving away from single-factor models towards algorithmic multifactorial models based on clinical, sonographic and biochemical factors for the better prediction of APO. Before the ratio is used as a criterion for time to delivery, prospective interventional studies are warranted to define the exact role of the sFlt-1/PIGF ratio as a predictor of APO in placenta related diseases.

\section{Conflict of Interest}

The authors declare that they have no conflict of interest.

\section{References}

[1] Rana S, Powe CE, Salahuddin S et al. Angiogenic factors and the risk of adverse outcomes in women with suspected preeclampsia. Circulation 2012; 125: 911-919

[2] Verlohren S, Herraiz I, Lapaire O et al. The sFlt-1/PIGF ratio in different types of hypertensive pregnancy disorders and its prognostic potential in preeclamptic patients. Am J Obstet Gynecol 2012; 206: 58.e1-58.e8

[3] Gómez-Arriaga PI, Herraiz I, López-Jiménez EA et al. Uterine artery Doppler and sFlt-1/PIGF ratio: prognostic value in early-onset pre-eclampsia. Ultrasound Obstet Gynecol 2014; 43: 525-532

[4] Graupner O, Lobmaier SM, Ortiz JU et al. sFlt-1/PIGF ratio for the prediction of the time of delivery. Arch Gynecol Obstet 2018; 298: 567-577

[5] Stepan H, Herraiz I, Schlembach D et al. Implementation of the sFlt-1/ PIGF ratio for prediction and diagnosis of pre-eclampsia in singleton pregnancy: implications for clinical practice. Ultrasound Obstet Gynecol 2015; 45: 241-246

[6] Villalaín C, Herraiz I, Valle L et al. Maternal and Perinatal Outcomes Associated With Extremely High Values for the sFlt-1 (Soluble fms-Like Tyrosine Kinase 1)/PIGF (Placental Growth Factor) Ratio. J Am Heart Assoc 2020; 9: e015548

[7] Mirkovic L, Tulic I, Stankovic S et al. Prediction of adverse maternal outcomes of early severe preeclampsia. Pregnancy Hypertens 2020; 22: $144-150$

[8] Hoffmann J, Ossada V, Weber M et al. An intermediate sFIt-1/PIGF ratio indicates an increased risk for adverse pregnancy outcome. Pregnancy Hypertens 2017; 10: 165-170

[9] Bednarek-Jędrzejek M, Kwiatkowski S, Ksel-Hryciów J et al. The sFlt-1/ PIGF ratio values within the $<38,38-85$ and $>85$ brackets as compared to perinatal outcomes. J Perinat Med 2019; 47: 732-740

[10] Chang YS, Chen CN, Jeng SF et al. The sFlt-1/PIGF ratio as a predictor for poor pregnancy and neonatal outcomes. Pediatr Neonatol 2017; 58: 529-533

[11] Stolz M, Zeisler H, Heinzl F et al. An sFlt-1:PIGF ratio of 655 is not a reliable cut-off value for predicting perinatal outcomes in women with preeclampsia. Pregnancy Hypertens 2018; 11: 54-60

[12] Simón E, Permuy C, Sacristán L et al. sFlt-1/PIGF ratio for the prediction of delivery within 48 hours and adverse outcomes in expectantly managed early-onset preeclampsia. Pregnancy Hypertens 2020; 22: 17-23

[13] Graupner O, Karge A, Flechsenhar $S$ et al. Role of sFlt-1/PIGF ratio and feto-maternal Doppler for the prediction of adverse perinatal outcome in late-onset pre-eclampsia. Arch Gynecol Obstet 2020; 301: 375-385

[14] Ciobanou A, Jabak S, De Castro $\mathrm{H}$ et al. Biomarkers of impaired placentation at 35-37 weeks' gestation in the prediction of adverse perinatal outcome. Ultrasound Obstet Gynecol 2019; 54: 79-86

[15] Friedman AM, Cleary KL. Prediction and prevention of ischemic placenta disease. Semin Perinatol 2014; 38: 177-182

[16] Levine RJ, Maynard SE, Qian C et al. Circulating angiogenic factors and the risk of preeclampsia. N Engl J Med 2004; 350: 672-683

[17] Herraiz I, Dröge LA, Gómez-Montes E et al. Characterization of the soluble fms-like tyrosine kinase- 1 to placental growth factor ratio in pregnancies complicated by fetal growth restriction. Obstet Gynecol 2014; 124 (2 Pt 1): 265-273

[18] Gaccioli F, Sovio U, Cook E et al. Screening for fetal growth restriction using ultrasound and the sFLT1/PIGF ratio in nulliparous women: a prospective cohort study. Lancet Child Adolesc Health 2018; 2: 569-581 
[19] Quezada MS, Rodríguez-Calvo J, Villalaín C et al. sFlt-1/PIGF ratio and timing of delivery in early-onset fetal growth restriction with antegrade umbilical artery flow. Ultrasound Obstet Gynecol 2020; 56: 549-556

[20] Mendoza M, Hurtado I, Bonacina E et al. Individual risk assessment for prenatal counseling in early-onset growth-restricted and small-for-gestational-age fetuses. Acta Obstet Gynecol Scand 2020. doi:10.1111/ aogs. 14032

[21] Mendoza M, Garcia-Manau P, Arévalo S et al. Diagnostic accuracy of firsttrimester combined screening for early-onset and preterm pre-eclampsia at 8-10 compared with 11-13 weeks' gestation. Ultrasound Obstet Gynecol 2021; 57: 84-90

[22] Sapantzoglou I, Wright A, Arozena MG et al. Ophthalmic artery Doppler in combination with other biomarkers in prediction of pre-eclampsia at 19-23 weeks' gestation. Ultrasound Obstet Gynecol 2021; 57: 75-83

[23] Papastefanou I, Wright D, Syngelaki A et al. Competing-risks model for prediction of small-for-gestational-age neonate from biophysical and biochemical markers at 11-13 weeks' gestation. Ultrasound Obstet Gynecol 2021; 57: 52-61

[24] Allotey J, Snell KI, Smuk M et al. Validation and development of models using clinical, biochemical and ultrasound markers for predicting pre-eclampsia: an individual participant data meta-analysis. Health Technol Assess 2020; 24 : 1-252

[25] American College of Obstetricians and Gynecologists; Task Force on Hypertension in Pregnancy. Hypertension in pregnancy. Report of the American College of Obstetricians and Gynecologists' Task Force on Hypertension in Pregnancy. Obstet Gynecol 2013; 122: 1122-1131

[26] German Society of Obstetrics and Gynecology (DGGG); Austrian Society of Obstetrics and Gynecology (OEGG); Swiss Society of Obstetrics and Gynecology (SGGG). Guidelines for Hypertensive Disorders in Pregnancy. Diagnosis and therapy. Updated May 2019. Accessed November 14, 2020 at: https://www.awmf.org/leitlinien/detail/II/015-018.html

[27] Stepan H, Hund M, Andraczek T. Combining Biomarkers to Predict Pregnancy Complications and Redefine Preeclampsia: The AngiogenicPlacental Syndrome. Hypertension 2020; 75: 918-926

[28] Brown MA, Magee LA, Kenny LC et al.; International Society for the Study of Hypertension in Pregnancy (ISSHP). The hypertensive disorders of pregnancy: ISSHP classification, diagnosis \& management recommendations for international practice. Pregnancy Hypertens 2018; 13: 291310

[29] Lai J, Syngelaki A, Nicolaides KH et al. Impact of new definitions of preeclampsia at term on identification of adverse maternal and perinatal outcomes. Am J Obstet Gynecol 2020. doi:10.1016/j.ajog.2020.11.004

[30] Duffy J, Hirsch M, Kawsar A et al.; iHOPE: International Collaboration to Harmonise Outcomes in Pre-Eclampsia. Outcome reporting across randomised controlled trials evaluating therapeutic interventions for preeclampsia. BJOG 2017; 124: 1829-1839

[31] Duffy J, Cairns AE, Richards-Doran D et al.; International Collaboration to Harmonise Outcomes for Pre-eclampsia (iHOPE). A core outcome set for pre-eclampsia research: an international consensus development study. BJOG 2020; 127: 1516-1526

[32] Bian X, Biswas A, Huang X et al. Short-Term Prediction of Adverse Outcomes Using the sFlt-1 (Soluble fms-Like Tyrosine Kinase 1)/PIGF (Placental Growth Factor) Ratio in Asian Women With Suspected Preeclampsia. Hypertension 2019; 74: 164-172
[33] Dröge LA, Perschel FH, Stütz $\mathrm{N}$ et al. Prediction of Preeclampsia-Related Adverse Outcomes With the sFlt-1 (Soluble fms-Like Tyrosine Kinase 1)/ PIGF (Placental Growth Factor)-Ratio in the Clinical Routine: A RealWorld Study. Hypertension 2021; 77: 461-471

[34] Perry H, Binder ], Kalafat E et al. Angiogenic Marker Prognostic Models in Pregnant Women with Hypertension. Hypertension 2020; 75: 755-761

[35] Broekhuijsen K, van Baaren G], van Pampus MG et al.; HYPITAT-II study group. Immediate delivery versus expectant monitoring for hypertensive disorders of pregnancy between 34 and 37 weeks of gestation (HYPITAT-II): an open-label, randomised controlled trial. Lancet 2015; 385: 2492-2501

[36] Chappell LC, Brocklehurst P, Green ME et al.; PHOENIX Study Group. Planned early delivery or expectant management for late preterm preeclampsia (PHOENIX): a randomised controlled trial. Lancet 2019; 394: 1181-1190

[37] Gordijn S], Beune IM, Thilaganathan B et al. Consensus definition of fetal growth restriction: a Delphi procedure. Ultrasound Obstet Gynecol 2016; 48: 333-339

[38] Lees CC, Stampalija T, Baschat A et al. ISUOG Practice Guidelines: diagnosis and management of small-for-gestational-age fetus and fetal growth restriction. Ultrasound Obstet Gynecol 2020; 56: 298-312

[39] Figueras F, Caradeux J, Crispi F et al. Diagnosis and surveillance of lateonset fetal growth restriction. Am J Obstet Gynecol 2018; 218 (2S): S790-S802.e1

[40] Lees CC, Marlow N, van Wassenaer-Leemhuis A et al.; TRUFFLE study group. 2 year neurodevelopmental and intermediate perinatal outcomes in infants with very preterm fetal growth restriction (TRUFFLE): a randomised trial. Lancet 2015; 385: 2162-2172

[41] Baschat AA. Neurodevelopment following fetal growth restriction and its relationship with antepartum parameters of placental dysfunction. Ultrasound Obstet Gynecol 2011; 37: 501-514

[42] Ganzevoort W, Thornton JG, Marlow N et al.; GRIT Study Group; TRUFFLE Study Group. Comparative analysis of 2-year outcomes in GRIT and TRUFFLE trials. Ultrasound Obstet Gynecol 2020; 55: 68-74

[43] Shinohara S, Uchida Y, Kasai M et al. Association between the high soluble fms-like tyrosine kinase- 1 to placental growth factor ratio and adverse outcomes in asymptomatic women with early-onset fetal growth restriction. Hypertens Pregnancy 2017; 36: 269-275

[44] Lobmaier SM, Figueras F, Mercade I et al. Angiogenic factors vs. Doppler surveillance in the prediction of adverse outcome among late-pregnancy small-for- gestational-age fetuses. Ultrasound Obstet Gynecol 2014; 43: 533-540

[45] Stampalija T, Thornton J, Marlow N et al.; TRUFFLE-2 Group. Fetal cerebral Doppler changes and outcome in late preterm fetal growth restriction: prospective cohort study. Ultrasound Obstet Gynecol 2020; 56: 173-181

[46] Hund M, Verhagen-Kamerbeek W, Reim M et al. Influence of the sFlt-1/ PIGF ratio on clinical decision-making in women with suspected preeclampsia-the PreOS study protocol. Hypertens Pregnancy 2015; 34: 102-115

[47] Klein E, Schlembach D, Ramoni A et al. Influence of the sFlt-1/PIGF Ratio on Clinical Decision-Making in Women with Suspected Preeclampsia. PLoS One 2016; 11: e0156013 